\title{
A descriptive spatial analysis of bovine tuberculosis in intensively controlled cattle farms in New Zealand
}

\author{
Thibaud PORPHYRE*, Joanna McKenZIE, Mark STEVENSON \\ EpiCentre, Institute of Veterinary, Animal, and Biomedical Sciences, Massey University, PB 11222, \\ Palmerston North 4442, New Zealand
}

(Received 13 March 2006; accepted 26 October 2006)

\begin{abstract}
We describe the temporal and geographical distribution of confirmed cases of bovine tuberculosis (TB) in a population of cattle in the south-east of the North Island of New Zealand. Data were derived from routine TB testing conducted between 1980 and 2003 and included details for 69 farms. Four six-year periods were defined to coincide with changes in depopulation strategies against the wildlife TB reservoir, the brushtail possum Trichosurus vulpecula. For the periods 1980 to 1985 and 1986 to 1991 the median annual incidence rate of TB was 0.4 and 4.7 cases per 1000 cattle-years at risk, respectively. For the period 1992 to 2003 the median annual incidence rate of TB decreased to 1.8 cases per 1000 cattle-years at risk, coincident with the use of poisoning to control possums in the surrounding forest park (a major possum habitat area). We identified clusters of TB cases adjacent to the forest park and found no evidence of spatio-temporal interaction of TB risk among farms. Our findings support the hypothesis that possums living in the forest park are a source of bovine TB in this area and that farm-to-farm spread of disease was not an important infection mechanism.
\end{abstract}

bovine tuberculosis / cattle farm / brushtail possum / spatial epidemiology

\section{INTRODUCTION}

Bovine tuberculosis (TB), caused by Mycobacterium bovis, is an infectious disease that causes economic, public health [4, 27], and ecological concerns around the world $[2,7,15]$. The incidence of bovine TB in New Zealand has been reduced through a national test-andslaughter policy which has been compulsory for all dairy and beef herds since the 1960 s $[1,10]$. Although this control program has largely been effective, disease eradication has not been achieved in some areas where $M$. bovis has persisted in the

* Corresponding author:

T.Porphyre@ massey.ac.nz major wildlife reservoir, the brushtail possum (Trichosurus vulpecula) [1].

Since the introduction of the New Zealand Biosecurity Act 1993 [24], research on bovine TB in New Zealand has concentrated on understanding the behaviour of the disease in cattle and the brushtail possum from a perspective of improving both disease and possum control strategies. Three key issues have been targeted for improvement: (1) routes of infection and the impact of TB in possum populations on TB in cattle herds [16,28,36]; (2) details of possum ecology at different levels of population density and infection status [6, 14,26,30]; and (3) tools for possum control $[3,31]$. A better understanding 
of the epidemiology of $M$. bovis in both cattle and possum populations has led to a refinement of TB and possum control strategies over time. Whereas the control strategies that have been applied are consistent with knowledge of the epidemiology of the disease in the two populations, there have been few (if any) studies that have critically evaluated their effectiveness.

This was a retrospective cohort study [12] used to describe the spatial and temporal patterns of bovine TB in an area where the disease has been present in cattle since the 1950s and was first detected in possums in 1969 [9] $^{1}$. Using routinely collected data our objectives were the following: (1) to describe the temporal and geographical patterns of confirmed TB infected cattle and how these were associated with changes in possum depopulation strategies that were applied throughout the study period; and (2) to investigate the contribution of neighbouring farm contacts to M. bovis transmission in cattle.

\section{MATERIALS AND METHODS}

The study area was located in the Wairarapa region, in the lower North Island of New Zealand. The township of Featherston (4106' 50.40” S - 175 $\left.{ }^{\circ} 19^{\prime} 39.72^{\prime \prime} \mathrm{E}\right)$ lies at the head of Lake Wairarapa and is bounded to the west by the Tararua and Rimutaka State Forest Parks and to the east and north by the Tauherenikau River (Fig. 1). The area is comprised of 6000 ha of pasture and is intensively farmed with a mixture of dairy, dry stock, and a small number of beef breeding herds. Approximately 9\% of the study area is comprised of land regarded as

\footnotetext{
${ }^{1}$ Shortridge E., Tuberculosis in cattle and opossums, in: Proc. Vet. Public Health Semin., Palmerston North, New Zealand, 1981, pp. 83-95.
}

suitable for possum habitat. Habitat areas are shelter belts (comprised of willows and scrub) along the Tauherenikau River and an area of approximately 100 ha of willows where the Tauherenikau River enters Lake Wairarapa. Gorse (Ulex europeus), manuka (Leptospermum scoparium), native scrub, and native forest cover large areas of the surrounding Tararua and Rimutaka foothills.

Possum control has been conducted on farms and in the surrounding forest-pasture margins, focussing on the first $400 \mathrm{~m}$ into the forest, in alternate years between 1991 and 2000. Up to 2000, control did not occur every year because of the low density of possums in this area. Since 2000 control activities have been applied annually in all high-risk areas in the study area. Large-scale aerial poisoning with sodiummonofluoroacetate (1080) was conducted up to a distance of $4 \mathrm{~km}$ into the forest park immediately to the north and south of the study area in mid 1993, and within the study area in April 1996 and again in June 2001.

The eligible population for this study was all cattle on farms within the boundaries of the study area that were registered in Agribase [35], the geographic database of New Zealand livestock farms (Tab. I). The study population was all cattle in all herds that had tuberculosis testing data available for the period 1 July 1980 to 30 June 2004 (inclusive), retrieved from the National Livestock Database (NLDB) [33]. For the purpose of this study, a year was defined as the period 1 July to 30 June (inclusive), representing the financial year used for administration of the TB control programme. Each year was labelled according to the first 6-month period of the financial year. The NLDB contained a number of instances where whole-herd testing was not conducted on particular farms in particular years. Where such farms had conducted whole herd tests in previous and successive years, we assumed the number 

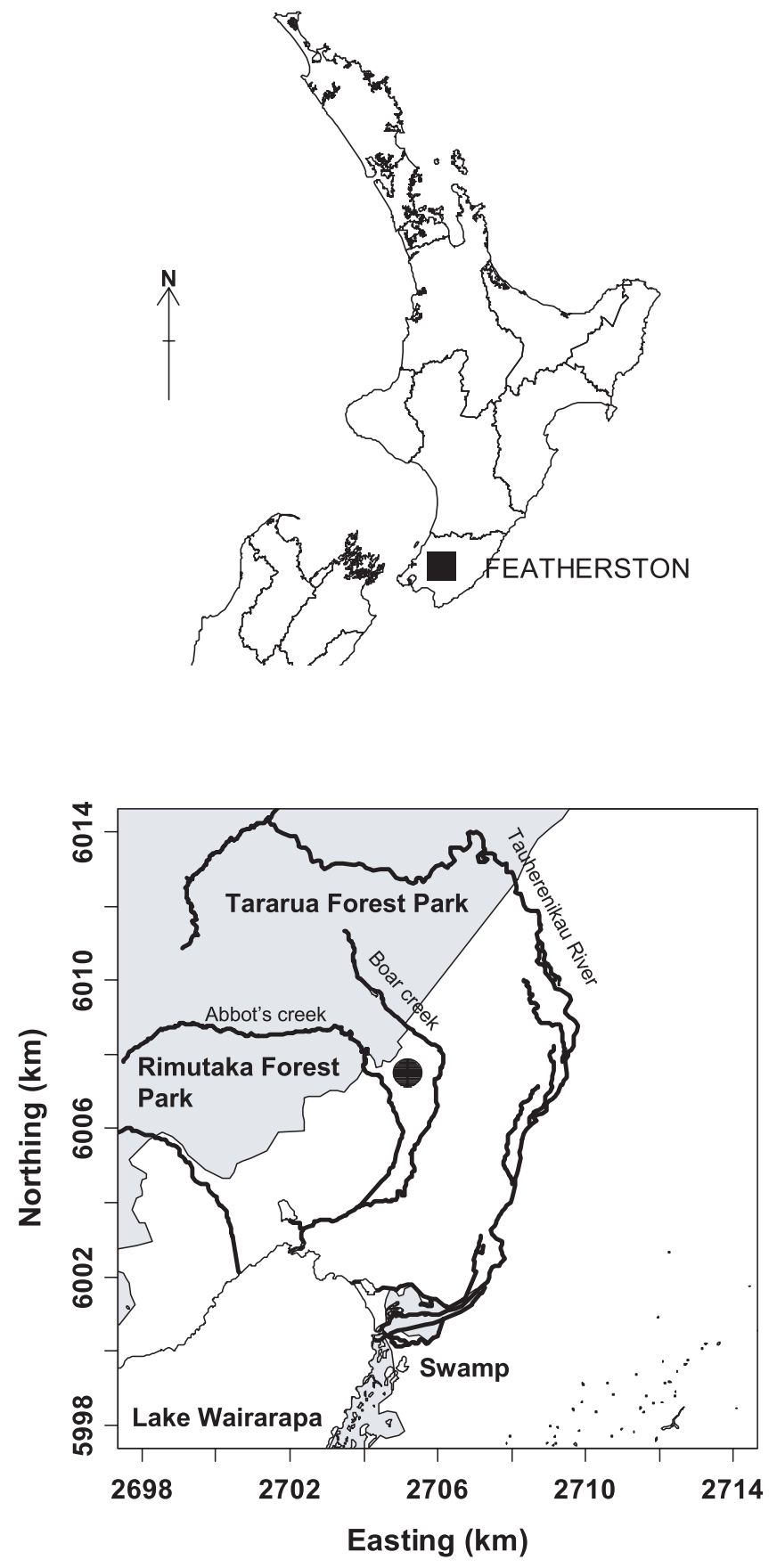

Figure 1. Map showing the location of the study area. Shaded areas represent forest park and swamp areas. Dark lines represent rivers/creeks. The filled circle represents the town of Featherston. 
Table I. Tuberculosis in the population of cattle in the Featherston area of New Zealand, 1980 to 2003. Counts of farms, herds and cattle at risk in the study area, stratified by herd type and time period.

\begin{tabular}{lrrrrr}
\hline Type & Farms & Herds & Cattle-years at risk & Mean $^{\mathrm{a}}(\mathrm{SD})$ & Median $^{\mathrm{a}}(\mathrm{Q} 1, \mathrm{Q} 3)$ \\
\hline 1980 to 1985 & & & & & \\
Beef & 10 & 11 & 7601 & $761(568)$ & $585(411,1026)$ \\
Dairy & 20 & 21 & 26659 & $1333(689)$ & $1395(954,1709)$ \\
Other & 2 & 2 & 139 & $70(41)$ & $70(56,84)$ \\
1986 to 1991 & & & & \\
Beef & 18 & 21 & 10018 & $557(710)$ & $319(66,652)$ \\
Dairy & 20 & 21 & 28264 & $1414(770)$ & $1405(943,1876)$ \\
Other & 3 & 3 & 452 & $151(202)$ & $60(35,221)$ \\
1992 to 1997 & & & & & \\
Beef & 26 & 30 & 17045 & $656(1041)$ & $139(27,735)$ \\
Dairy & 19 & 22 & 34371 & $1809(687)$ & $1725(1292,2405)$ \\
Other & 10 & 10 & 2150 & $215(365)$ & $75(40,152)$ \\
1998 to 2003 & & & & & \\
Beef & 25 & 32 & 16592 & $664(1240)$ & $99(45,439)$ \\
Dairy & 20 & 24 & 43235 & $2162(747)$ & $2069(1526,2637)$ \\
Other & 19 & 19 & 4136 & $218(557)$ & $41(16,105)$ \\
Total & 69 & 90 & 190665 & $2764(3494)$ & $567(54,5361)$ \\
\hline
\end{tabular}

${ }^{a}$ Number of cattle-years at risk per farm. SD: Standard deviation. Q1: First quantile. Q3: Third quantile.

of animals at risk in the missing year was equal to the average of the number tested in previous and successive years. On the contrary, if more than one whole herd test was completed in a year then the mean number tested was used to represent the herd size for that year.

On the basis of details recorded in the NLDB, farms were categorised into one of three enterprise types: beef, dairy, and other (a category used to describe miscellaneous enterprise types such as those rearing dairy heifer replacements on contract).

The outcome of interest was a confirmed diagnosis of TB that occurred between 1 July 1980 and 30 June 2004 (inclusive). An animal was confirmed TBpositive if either of the two following diagnostic criteria was met: (1) a caudal fold test (CFT) positive animal with a lesion at slaughter that was either histologically typical of bovine tuberculosis and/or $M y$ cobacterium bovis was isolated from the lesion; and (2) an animal identified with a lesion at routine slaughter that was either histologically typical of bovine tuberculosis and/or Mycobacterium bovis was isolated from the lesion.

We defined four six-year time periods that broadly coincided with possum control policies that were applied in the Featherston area from 1980 to 2003 . These were the following: (1) 1980 to 1985: annual test-and-slaughter control in cattle with no possum controls; (2) 1986 to 1991: annual test-and-slaughter of cattle, with some variation in testing policy compared with the previous period, and no possum controls; (3) 1992 to 1997: annual test-andslaughter of cattle with possum controls applied every second year on farmland 
and the forest-pasture margin, and with aerial control in the forest in April 1996; and (4) 1998 to 2003: annual test-andslaughter of cattle, plus annual possum controls on farmland and the forest-pasture margin from 2000, with aerial control in the forest in June 2001. Defining the time periods in this way allowed us to crudely evaluate the effectiveness of the various TB control strategies that were applied over an extended period of time, assuming that the effect of any given control strategy was reflected relatively quickly in the results of cattle TB testing.

East and north coordinates of the centroid of each farm in the study area were determined using a Geographic Information System. The largest parcel of land provided the centroid coordinate for those farms comprised of two or more noncontiguous land areas.

Crude annual TB incidence rates were calculated as the total number of confirmed TB cases within each 12-month period divided by the total number of cattle tested in annual whole herd tests [12]. Crude period TB incidence rates were the total number of confirmed TB cases identified within each six-year period divided by the total number of cattle years tested in annual whole herd tests for the same time frame. On account of instability in the data caused by the presence of farms with relatively small numbers of cattle, empirical Bayes adjusted estimates of incidence rate were calculated [19]. Using this approach, the crude period TB incidence rate was weighted towards the study population mean with the magnitude of the weight inversely proportional to the number of cattle tested on each farm.

A common explanation given by herd managers for the ongoing presence of TB in this area is that disease is transmitted from farm to farm as a result of contact with infected neighbours. If this was true, the risk of disease would be increased for those farms that were close in space and time to farms identified as TB positive. To test this hypothesis the presence of spatio-temporal interaction of TB risk was investigated using the spacetime $K$-function [11] implemented in the SPLANCS package $[5,32]$ in $\mathrm{R}$ version 2.01 (R Development Core Team, 2005). Using this method, the metric $D_{0}(s, t)$ was computed to quantify the proportional change in TB risk due to space-time interaction. For the purpose of this analysis, we defined a case as a farm placed under movement control resulting from detection of at least one confirmed TB-positive cattle in the herd. Since farms may shift from infected to clear status by returning two consecutive tests, at least six months apart, without evidence of disease [34], case farms were returned to the risk set and considered eligible for re-infection after a minimum period of two years. The estimate $D_{0}(s, t)$ was computed from the cumulative number of expected case-farm events within distance $s$ and time $t$ from an arbitrary selected case farm $K(s, t)$, compared with the product of the expected number of case farms per unit space $K_{1}(s)$ and time $K_{2}(t)$ :

$$
D_{0}(s, t)=\frac{K(s, t)}{K_{1}(s) K_{2}(t)}-1
$$

Here, a value of $D_{0}(s, t)$ equal to 1 at any given distance and time separation indicates that the risk of TB from an arbitrarily selected farm is $100 \%$ greater than that expected under the assumption that spacetime interaction does not exist [11]. A formal test for the presence of space-time interaction was performed by conducting 999 Monte Carlo simulations in which each of the $n$ case events were labelled with the $n$ time markers. We defined $D(s, t)$ as the difference between the observed spacetime $K$-function $K(s, t)$, and the space-time $K$-function that would exist in the absence of space-time interaction $K_{1}(s) K_{2}(t)$. For each simulation, the sum of $D(s, t)$ over all $s$ and $t$ was obtained. To test the null 
hypothesis that space-time interaction of farm-level TB risk did not exist, the sum of $D(s, t)$ for the observed data was ranked among the empirical frequency of the 999 sums. If the sum of $D(s, t)$ for the observed data ranked in the upper 5\% quantile of the empirical distribution, the null hypothesis would be rejected and the inference would be that the space-time interaction observed was unlikely to have occurred by chance at the alpha level of 0.05 .

The location of cluster(s) of TB-positive cattle on farms for each period was evaluated using the spatial scan statistic of Kulldorff and Nagarwalla [18]. This method is based on creating a series of circular windows of variable radius around each confirmed TB-positive farm that occurred during each period. Each circular window was set to contain a pre-determined fraction of the population which was limited to $15 \%$ in order to focus on localised clusters [25]. The number of cases and animals within each window was summed and compared with the number of cases outside the window. The scan statistic tested the significance of the frequency of disease within each window by assuming that the expected number of cases followed a Poisson distribution and was proportional to the population size within the window. The resulting likelihood ratios were sorted in descending order and the window with the largest maximum likelihood value designated as the 'most likely' spatial cluster. $P$-values were computed by comparing each window's likelihood ratio statistic with the expected distribution generated from re-labelling of the data using a Monte Carlo procedure.

\section{RESULTS}

The crude annual incidence rate of bovine TB as a function of year of testing is shown in Figure 2. Amongst the 190665 cattle-years at risk between 1980 and 2003, 430 cattle were confirmed TBpositive, giving a crude incidence rate of 2.3 cases per 1000 cattle-years at risk for the 24 -year period ( $95 \%$ CI $2.1-2.5$ cases per 1000 cattle-years at risk). Amongst the confirmed TB-positive cattle, $44 \%$ were from beef enterprises $(n=191), 51 \%$ were from dairy enterprises $(n=220)$ and the remainder $(n=19)$ were from farm enterprises classified as 'other'.

The number of cattle tested per annum increased throughout the study period from approximately 6000 in 1980 to 10000 in 2003. For the period 1981 to 1986 the crude annual TB incidence rate in cattle was less than 1 case per 1000 cattle-years at risk. From 1987 to 1993 there was a six fold increase in crude annual TB incidence to a maximum of 6.1 cases per 1000 cattleyears at risk. In 1994 the incidence rate of TB decreased to less than 4 cases per 1000 cattle-years at risk, and continued to decline each year until 2000. In the last three years of the study, two peaks of TB incidence rate occurred, one in 2001 and the other in 2003. These peaks coincided with a large outbreak of TB in a different herd in each year.

Overall, there were 17, 154, 187 and 72 confirmed TB cases detected between 1980 and 1985, 1986 and 1991, 1992 and 1997, 1998 and 2003, respectively. Dairy cattle represented $53 \%, 45 \%, 47 \%$ and $74 \%$ of cases for each period whereas beef farms accounted for $47 \%, 50 \%, 47 \%$ and $25 \%$ of cases for each period, respectively.

Figures $3 \mathrm{a}$ to $3 \mathrm{~d}$ show the spatial distribution of the empirical Bayes estimates of the farm-level TB incidence rate in each period. From 1980 to 1985 the small number of TB-cases occurred predominantly on farms bordering the forest park and around the head of Lake Wairarapa. During the two periods from 1986 to 1991 and 1992 to 1997 , TB cases were distributed across farms throughout the Featherston area. However, the highest adjusted incidence continued to occur on farms along 


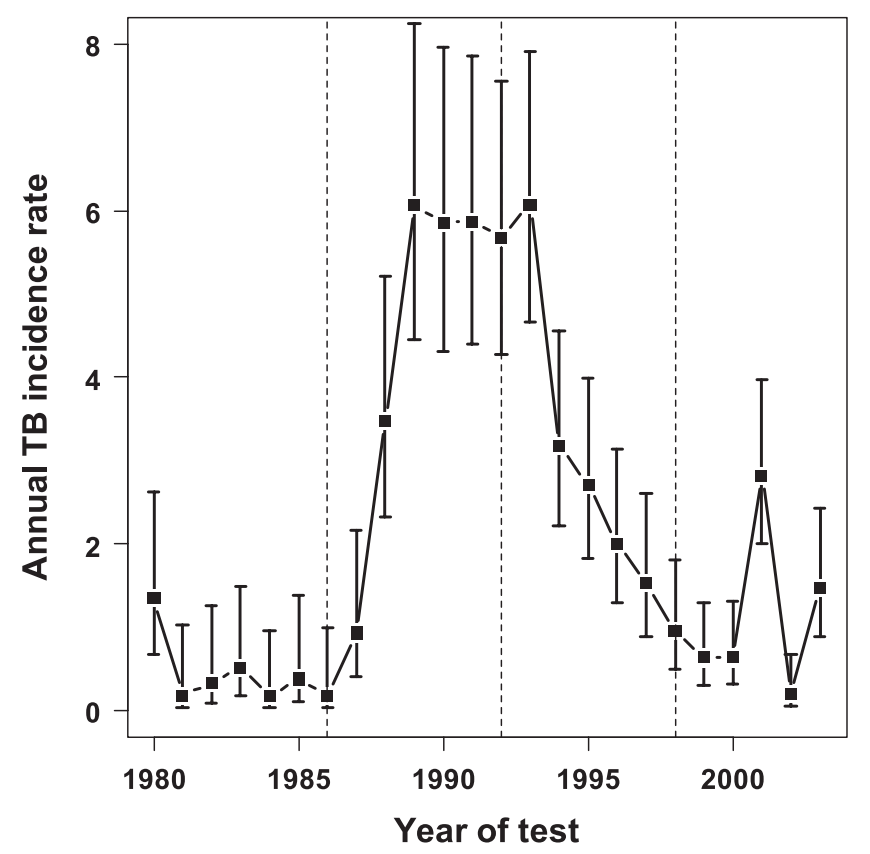

Figure 2. Tuberculosis in the population of cattle in the Featherston area of New Zealand, 1980 to 2003. Annual incidence rate of bovine TB (and 95\% confidence intervals) expressed as the number of cases per 1000 cattle-years at risk. Vertical dashed lines indicate the time periods described in the text.

the forest park boundaries. From 1998 to 2003 the adjusted incidence rate of disease was low compared with the previous two years (Fig. 2) with less localisation of cases along the forest boundaries. Approximately half of the cases observed in this period ( 37 of 72 ) were on two dairy farms in the east of the study area along the Tauherenikau River (Fig. 3d).

A surface plot showing the proportional change in TB risk as a function of distance and time from an arbitrarily selected case farm is shown in Figure 4. In Figure 4, values of $D_{0}(s, t)$ at the distance and time separations evaluated were predominantly less than zero, providing no evidence of additional TB risk for farms that were close in space and time to TB-positive farms. The Monte Carlo test for space-time interaction was not significant at the alpha level of 0.05 (Monte Carlo test statistic -238; $P=0.255)$.

Figures $5 \mathrm{a}$ to $5 \mathrm{~d}$ show the location of the most likely, the second most likely, and the third most likely clusters of TBpositive cattle in the Featherston area for each period. The number of farms in each cluster, the number of observed and expected cattle cases, and the incidence rate ratio (that is, the observed incidence rate divided by the expected incidence rate) are shown in Table II. These support the pattern of TB incidence rates shown in Figure 3. During the early period (1980 to 1985) TB was clustered on farms in the south of the study area. Disease remained in this location throughout 1986 to 1991 when the number of observed TB cases on farms in the most likely cluster was 18 times higher than the expected number 

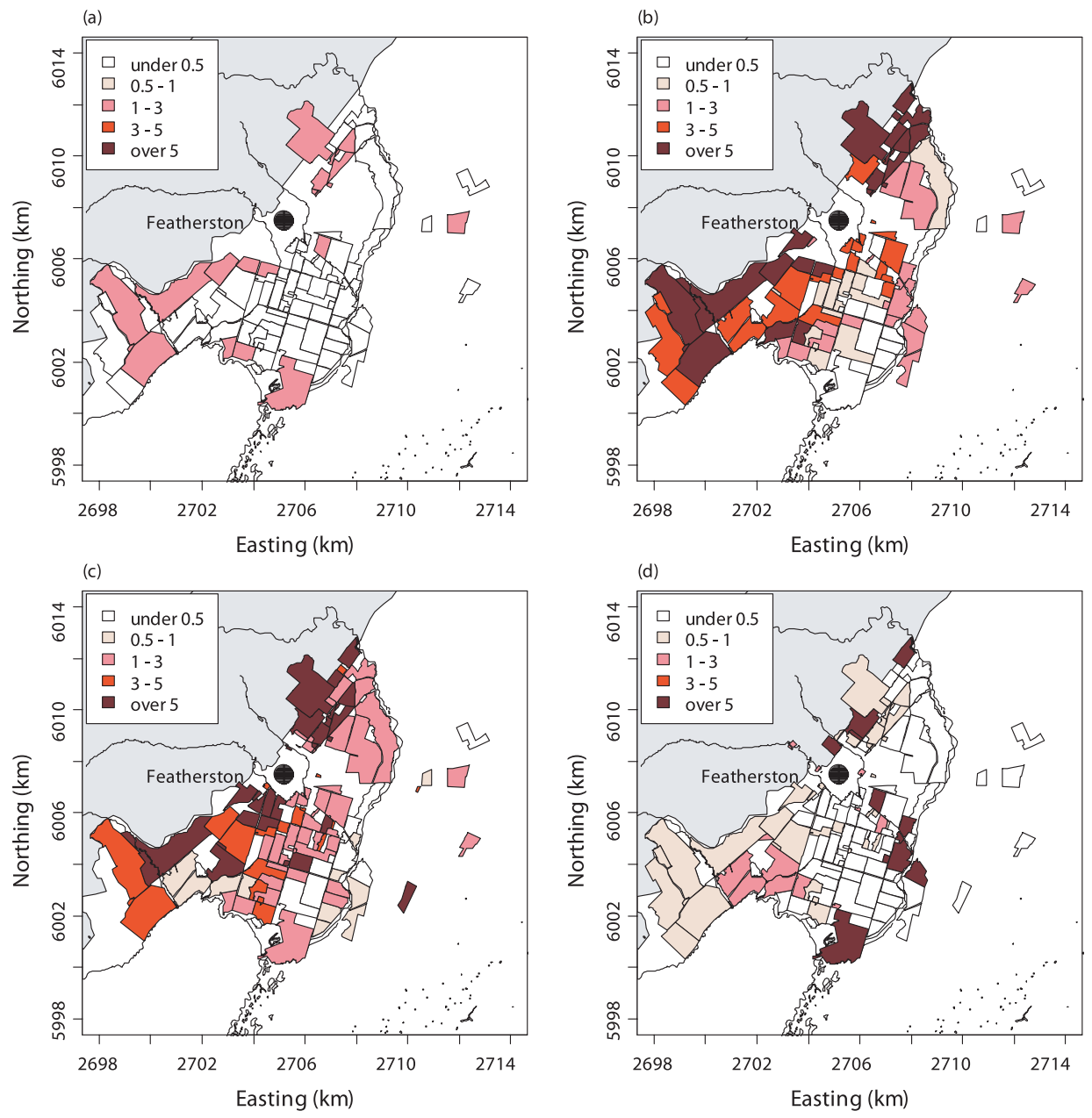

Figure 3. Tuberculosis in the population of cattle in the Featherston area of New Zealand, 1980 to 2003. Choropleth maps showing the empirically Bayesian-adjusted tuberculosis incidence rate in cattle per farm (expressed as cases per 1000 cattle-years at risk) for: (a) 1980 to 1985, (b) 1986 to 1991, (c) 1992 to 1997, and (d) 1998 to 2003.

of cases given the number of cattle on these farms (Tab. II). An additional cluster of TB occurred during this second period on farms in the north of the study area. During the third period (1992 to 1997) TB remained clustered in the south, but on a smaller number of farms compared with the previous period. The cluster in the north also remained but included a smaller number of farms. One additional cluster occurred on a farm in the centre of the study area that had a high incidence of TB cases during 1993 and 1994. During 1998 to 2003 a multi-farm cluster occurred immediately to the north of Featherston. The absence of clusters in the south and the 


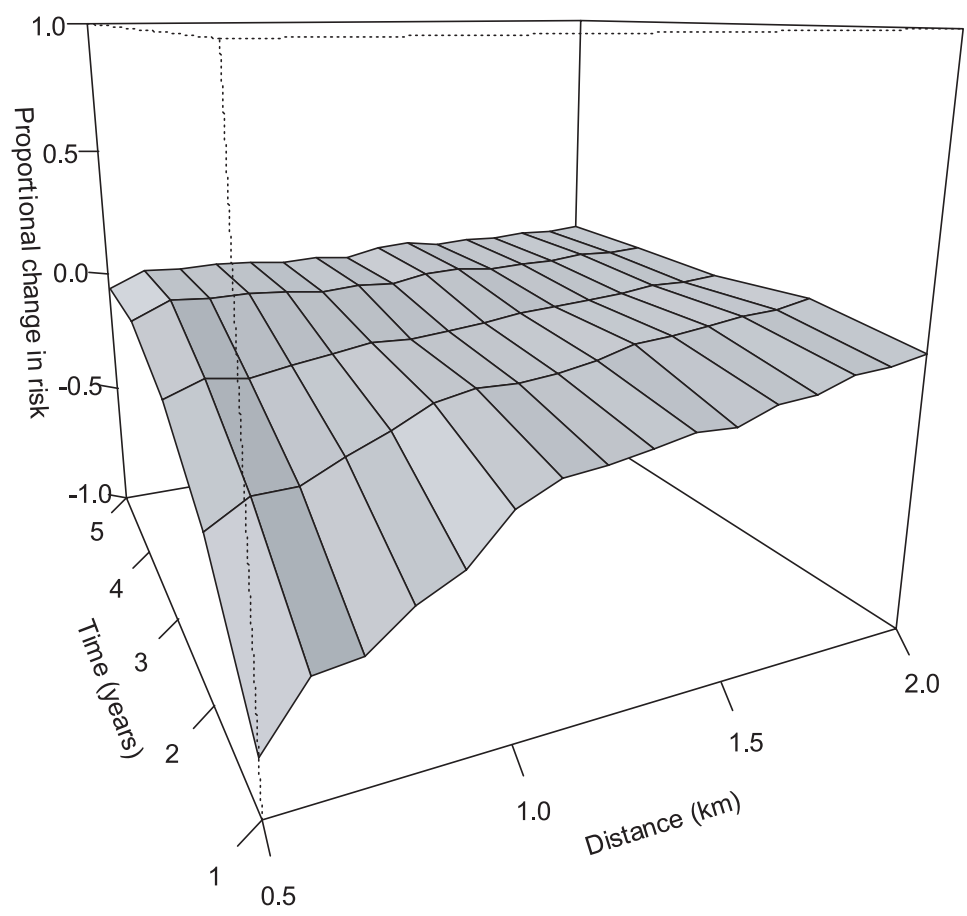

Figure 4. Tuberculosis in the population of cattle in the Featherston area of New Zealand, 1980 to 2003. Surface plot showing the proportional increase in farm tuberculosis risk as a function of distance and time.

extreme north of the study area indicate that TB cases tended to be more sporadically distributed between 1998 and 2003.

Acknowledging that the spatial scan statistic may be influenced by outliers, cluster analyses were repeated excluding high-incidence outbreaks ${ }^{2}$. An outlier was defined as a farm with a Bayes adjusted estimate of incidence rate in the upper $2.5 \%$ of the observed distribution. Identifying the same clusters of TB following backward stepwise exclusion of defined outliers provided reassurance of the robustness of the inferences made about the spatial pattern of disease for the four study periods.

\footnotetext{
${ }^{2}$ Kulldorff M., SaTScan ${ }^{\text {TM }}$ User Guide for version 7.0, in: SaTScan Technical Documentation [on line] (2006) http://www.satscan.org/ techdoc.html [consulted 24 August 2006].
}

Figure 6 shows the proportion of farmyears that were TB positive as a function of distance from the forest park boundary. Two eight-year time periods were considered: before (1988 to 1995) and after (1996 to 2003) the introduction of aerial possum controls. Before aerial control was applied, the proportion of TB positive farm-years was inversely proportional to distance from the forest park boundary. After aerial control was applied the association between the proportion of TB positive farm-years and distance from the forest park was not as clearly defined.

\section{DISCUSSION}

The objective of this study was to describe the spatial and temporal distribution 
(a)

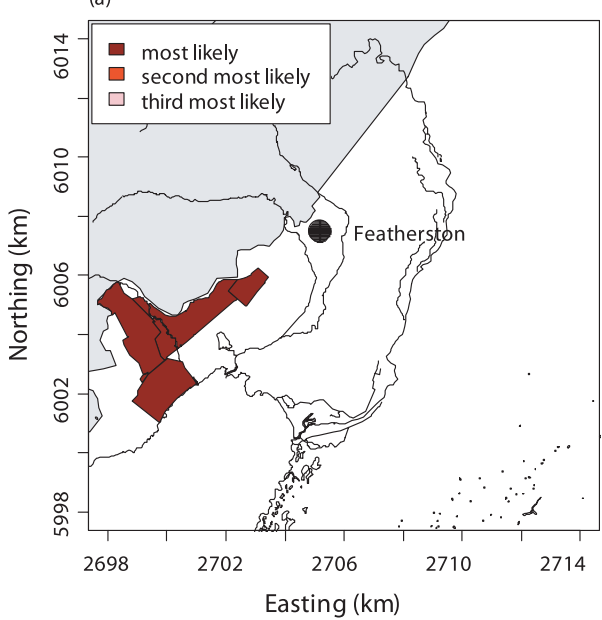

(c)

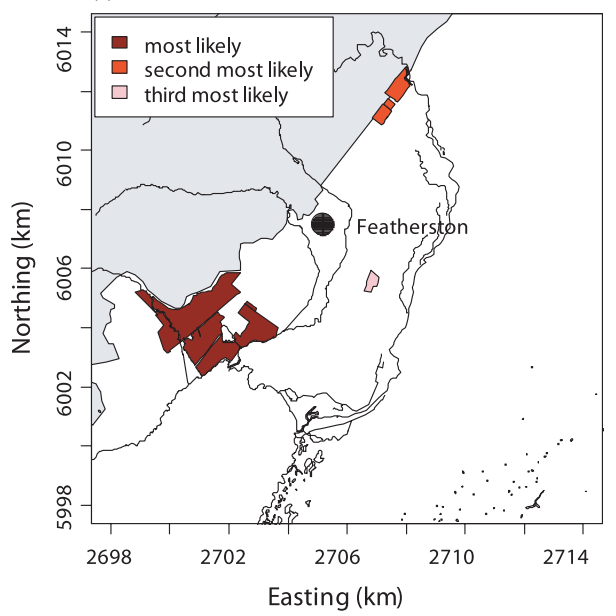

(b)

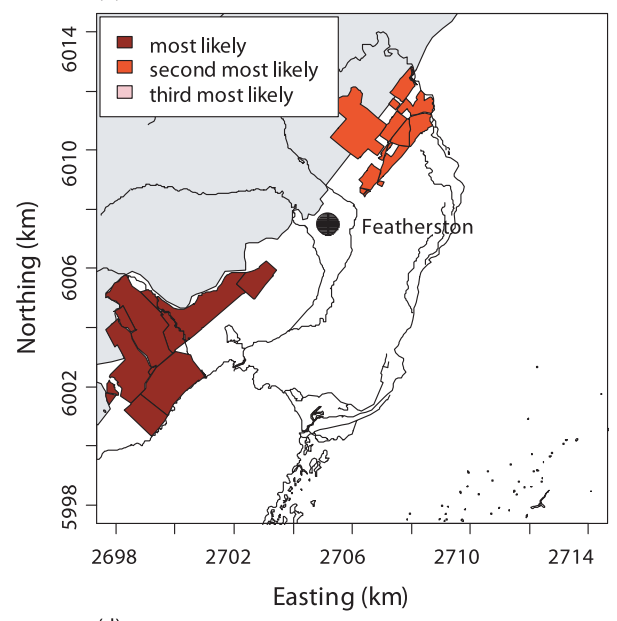

(d)

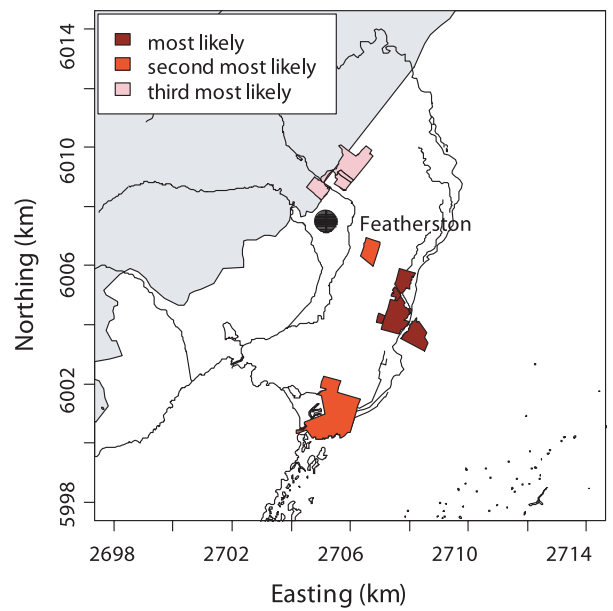

Figure 5. Tuberculosis in the population of cattle in the Featherston area of New Zealand, 1980 to 2003. Location of the most likely, second most likely and third most likely spatial clusters of TB-positive cattle for: (a) 1980 to 1985, (b) 1986 to 1991, (c) 1992 to 1997, and (d) 1998 to 2003.

of TB in a population of cattle in the south of the North Island of New Zealand and to describe changes in the distribution of TB in this population that occurred in response to control strategies applied to the wildlife reservoir of disease, the brushtail possum. To achieve this goal we restricted our analysis to confirmed TB cases, in which infection with $M$. bovis was confirmed by histopathology or culture. It is possible that some cases of bovine TB were missed due to TB lesions not being detected during post mortem examination. We believe that this is unlikely to have introduced major bias as the sensitivity of post mortem examination was likely to be similar across farms within any given period. Given the performance of the caudal fold test (sensitivity $75 \%-85 \%$; specificity $>99.6 \%$, $[20,29])$ can vary among testers, and is 
Table II. Tuberculosis in the population of cattle in the Featherston area of New Zealand, 1980 to 2003. Details of statistically significant spatial clusters of bovine tuberculosis cases, stratified by time period.

\begin{tabular}{|c|c|c|c|c|c|}
\hline Cluster & Farms & Observed & Expected & IRR & $P$ \\
\hline \multicolumn{6}{|l|}{1980 to 1985} \\
\hline Most likely & 3 & 7 & 1.74 & 4.02 & 0.027 \\
\hline \multicolumn{6}{|l|}{1986 to 1991} \\
\hline Most likely & 5 & 75 & 4.18 & 17.94 & $<0.001$ \\
\hline Second most likely & 4 & 13 & 6.15 & 2.11 & $<0.001$ \\
\hline \multicolumn{6}{|l|}{1992 to 1997} \\
\hline Most likely & 5 & 52 & 25.80 & 2.02 & $<0.001$ \\
\hline Second most likely & 3 & 8 & 1.01 & 7.90 & 0.002 \\
\hline Third most likely & 1 & 11 & 3.14 & 3.51 & 0.024 \\
\hline \multicolumn{6}{|l|}{1998 to 2003} \\
\hline Most likely & 1 & 22 & 3.47 & 6.34 & $<0.001$ \\
\hline Second most likely & 1 & 16 & 1.89 & 8.45 & $<0.001$ \\
\hline Third most likely & 6 & 9 & 0.70 & 12.79 & $<0.001$ \\
\hline
\end{tabular}

IRR: Incidence rate ratio.

associated with animal- and farm-level factors, restricting our dataset to confirmed TB cases made the data more comparable between farms and between years.

Little published information is available regarding the length of time between application of possum controls and the resulting effect on TB incidence in cattle. Data exist concerning the effect of aerial 1080 poisoning and ground control on possum populations. Morgan and Hickling [22] reported that aerial use of 1080 poison baits in New Zealand forests typically kills between $80 \%$ and $95 \%$ of possums. Given that 1080 poisoning results in a quick death (within $2 \mathrm{~h}$ ) and does not accumulate in the environment [37] we believe that 1080 poisoning, by drastically reducing possum numbers, reduces the transfer of infection from possums to cattle with a rate dependent on both the effectiveness of application of poisoning and the time taken to develop reactor status in cattle. Given that $M$. bovis has been shown to induce a response to the tuberculin skin test within 1-2 months following infection (depending on the size of infectious dose, genotype, and immune status of the host $[20]^{3}$ ) and that cattle on each farm are tested annually, the impact of possum control using 1080 poisoning would be reflected relatively quickly in TB test results. If control is conducted early in the financial year then the effect will be reflected in cattle TB testing results from the same year. However, if applied later in the year it will predominantly be reflected in the results from the following year. Control of possums based on trapping and cyanide poison has been shown to be just as effective as aerial 1080 poisoning [13,21] however these methods may need to be applied for a longer period of time to achieve similar levels of efficacy. It was for this reason that we used a series of six-year

\footnotetext{
${ }^{3}$ DEFRA, Bovine Tuberculosis, in: Disease fact-sheet [on line] (2006) http://www.defra. gov.uk/animalh/diseases/notifiable/disease/tb. htm [consulted 25 August 2006].
} 


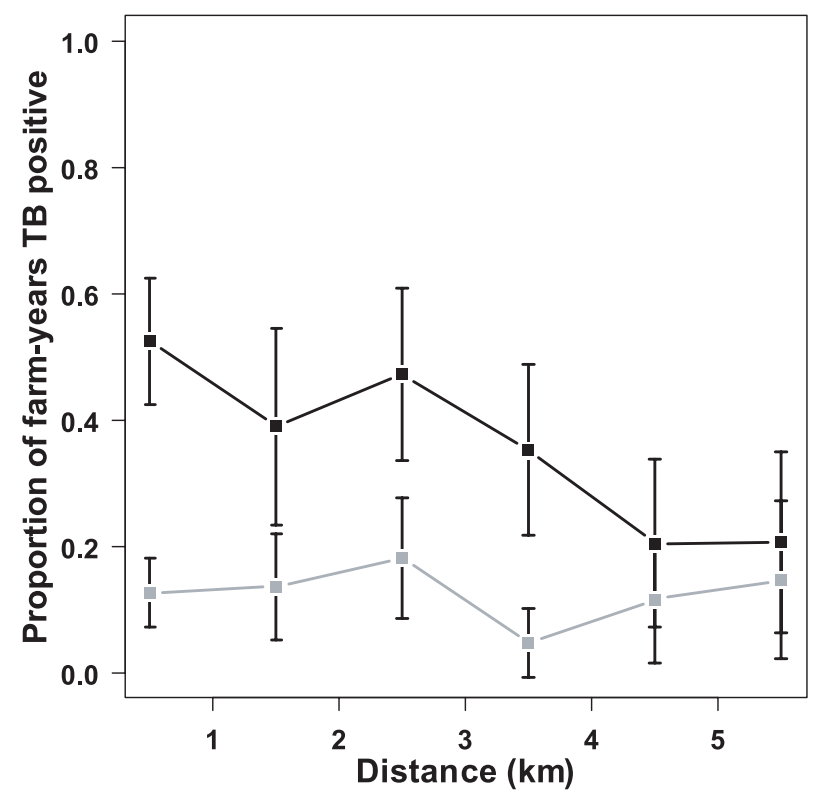

Figure 6. Tuberculosis in the population of cattle in the Featherston area of New Zealand, 19882003. Proportion of farm-years that were tuberculosis-positive as a function of farm distance from the forest boundary during the 8-year periods before (1988 to 1995, black) and after (1996 to 2003, grey) the introduction of aerial possum control. Vertical bars represent $95 \%$ confidence intervals.

periods to evaluate the temporal relationship between possum control strategies and disease incidence.

The pattern of TB incidence rate over time, the Bayes adjusted incidence maps, and the scan statistic analyses show that changes in the spatial and temporal pattern of TB were associated with spatial and temporal changes in possum control strategies applied throughout the study period. Despite the introduction in 1991 of a control strategy that was based on trapping possums on farmland and the forestpasture margin there was no decline in annual TB incidence in cattle until 1994. This strongly suggests that this ground-based control had no immediate impact on the major source of TB-infected possums. The first major decline in TB incidence in 1994 coincided with the application of aerial 1080 control up to $4 \mathrm{~km}$ into the forest on the northern and southern boundaries of the study area. The incidence continued to decline, with application of aerial control in the study area in April 1996 and again in June 2001. Patchy control, which resulted from restrictions in control methods used near waterways, in water catchment areas, and within the town boundary is a logical explanation for the residual TB evident during 1998 to 2003. The presence of the spatial cluster to the north of Featherston during 1998 to 2003 supports the hypothesis that residual, TB infected possums remained in the Boar Creek area and continued to infect cattle on nearby farms following aerial control in 1996 and 2000 , since this water catchment area was not intensively controlled until 2002. Possum control has been intensified between 2000 and 2003 and residual possum populations have been reduced. In spite of this, the continued low level of cattle infection that occurred throughout 2002 and 2003 
suggest that there were sufficient numbers of infected possums remaining to cause infection on farms both neighbouring the forest (as in 2002) and on other farms independent of their distance from the forest (as in 2001 and 2003).

Although it is widely accepted that tuberculous possums play an important role in the transmission of TB among cattle in New Zealand [17,23], we are aware of no studies that have examined the role of neighbouring farms in the spread of disease. Spread of TB from farm to farm may occur as a result of close contact between animals at farm boundaries, during herd movements either at milking time (in the case of dairy cattle) or for pasture management. Although it would have been desirable to have details of location of grazing areas for all herds on each farm for the duration of this study, this was not possible and so a suitable proxy for farm-tofarm contact was derived from the calculated distance between property centroids. We recognise that this approach may be subject to bias (particularly for farms comprised of multiple land parcels) and that the amount of contact between neighbouring farms may be underestimated. However, only eight farms were comprised of noncontiguous land parcels and these were separated from the main parcel by an average minimum distance of $4.9 \mathrm{~km}(95 \%$ CI $2.8 \mathrm{~km}-7.1 \mathrm{~km})$. Amongst these eight farms, five were known to have not used the parcel for grazing. Thus, the limited number of multiple parcel farms and the relatively limited scale of distance used to identify the spatial component of spacetime interaction (up to $2 \mathrm{~km}$ ) made the use of property centroids a reasonable approach.

The absence of spatio-temporal interaction of TB risk among farms (Fig. 4) and the presence of spatial clusters of cases (Fig. 5) is suggestive of a common (point or continuous) exposure to infection. The persistent detection of clusters of TB adja- cent to the forest throughout the four study periods and the reduction in the incidence rate of TB associated with control activities aimed at reducing possum numbers, provides further supportive evidence for the hypothesis that infected possums from the forest are a major vector for TB in this area.

Before the onset of aerial possum controls, the effect of distance from the forest margin was inversely related to the proportion of farm-years that were TB-positive. After aerial possum control was applied, no clear relationship could be identified between distance from the forest margin and the proportion of farm-years that were TB-positive (Fig. 6). The combination of periodic aerial control over a large area of forest plus annual ground-based control in the forest-pasture margin appears to have had a relatively higher impact on the cattle TB incidence on farms within $4 \mathrm{~km}$ of the forest compared with those further away. We hypothesise that there are two sources of TB possums arising from the forest. The first is infected possums whose home ranges are in the forest-pasture margin and either overlap with, or are adjacent to, farms neighbouring the forest. Infectious possums from this group have a higher risk of contacting cattle on adjacent farms compared with farms located further away. The second source is infected possums that make long distance forays from deeper in the forest onto farmland. This explanation is reasonable given that $20 \%$ to $30 \%$ of juvenile possums travel, on average, a distance of $5 \mathrm{~km}$ from their place of birth (range $2 \mathrm{~km}$ to $41 \mathrm{~km}$ ) to establish their adult home range [8].

In conclusion, our findings support the thesis that possums living in the forest park are the major source of bovine TB in this area. These analyses also support the hypothesis that the application of effective possum control methods (aerial poison drops) results in a substantial reduction in the incidence rate of $\mathrm{TB}$ in cattle. The sporadic distribution of infected 
farms that occurred after the introduction of aerial possum controls suggests that infected possums making long-distance movements from the forest onto farmland, other wildlife sources of $\mathrm{TB}$, or cattle movements are additional factors that have become more prominent as a source of infection in this area over time.

\section{ACKNOWLEDGEMENTS}

This study was contracted by the Animal Health Board (Project No. R-50634). AgriQuality New Zealand and the Greater Wellington Regional Council staff based at Masterton are thanked for their assistance.

\section{REFERENCES}

[1] Anonymous, Cattle Tuberculosis - History of TB control scheme, Surveillance (1986) 13:4-8.

[2] Ayele W., Neill S., Zinsstag J., Weiss M., Pavlik I., Bovine tuberculosis: An old disease but a new threat to Africa, Int. J. Tuberc. Lung Dis. (2004) 8:924-937.

[3] Ball S., Effectiveness of possum control in relation to patchiness, Animal Health Board contractual report No. R-10575, Wellington, New Zealand, 2003.

[4] Biet F., Boschiroli M., Thorel M., Guilloteau L., Zoonotic aspects of Mycobacterium bovis and Mycobacterium avium-intracellular complex (MAC), Vet. Res. (2005) 36:411436.

[5] Bivand R., Gebhardt A., Implementing functions for spatial statistical analysis using the R language, J. Geogr. Syst. (2000) 2:307317.

[6] Caley P., Is the spatial distribution of tuberculous possums influenced by den "quality"? N. Z. Vet. J. (1996) 44:175-178.

[7] Cosivi O., Grange J., Daborn C., Raviglione M., Fujikura T., Cousins D., Robinson R., Huchzermeyer H., de Kantor I., Meslin F.-X., Zoonotic Tuberculosis due to Mycobacterium bovis in developing countries, Emerg. Infect. Dis. (1998) 4:59-70.

[8] Cowan P., Clout M., Possums on the move: activity patterns, home ranges, and dispersal, in: Montague T. (Ed.), The Brushtail
Possum: biology, impact and management of an introduced marsupial, Manaaki Whenua Press, Lincoln, New Zealand, 2000, pp. 24-34.

[9] Davidson R., Tuberculosis in possums, Surveillance (1991) 18:16.

[10] Davidson R., Control and eradication of animal diseases in New Zealand, N. Z. Vet. J. (2002) 50:6-12.

[11] Diggle P., Chetwynd A., Haggkvist R., Morris S., Second-order analysis of spacetime clustering, Stat. Methods Med. Res. (1995) 4:124-136.

[12] Dohoo I., Martin W., Stryhn H., Veterinary epidemiologic research, AVC Inc., Charlottetown, Prince Edward Island, Canada, 2003.

[13] Eason C., Warburton B., Henderson R., Toxicants used for possum control, in: Montague T. (Ed.), The brushtail possum: biology, impact and management of an introduced marsupial, Manaaki Whenua Press, Lincoln, New Zealand, 2000, pp. 154-163.

[14] Green W., Coleman J., Movement of possums (Trichosurus vulpecula) between forest and pasture in Westland, New Zealand: implication for bovine tuberculosis transmission, N. Z. J. Ecol. (1986) 9:57-69.

[15] Hammerschmidt D., Bovine tuberculosis: still a world health problem, J. Lab. Clin. Med. (2003) 141:359-360.

[16] Jackson R., Cooke M., Coleman J., Morris R., de Lisle G., Yates G., Naturally occurring tuberculosis caused by Mycobacterium bovis in brushtail possums (Trichosurus vulpecula). III. Routes of infection and excretion, N. Z. Vet. J. (1995) 43:322-327.

[17] Jackson R., The role of wildlife in Mycobacterium bovis infection of livestock in New Zealand, N. Z. Vet. J. (2002) 50:49-52.

[18] Kulldorff M., Nagarwalla N., Spatial disease clusters: detection and inference, Stat. Med. (1995) 14:799-810.

[19] Marshall R., Mapping disease and mortality rates using empirical Bayes estimators, Appl. Stat. (1991) 40:283-294.

[20] Monaghan M., Doherty M., Collins J., Kazda J., Quinn P., The tuberculin test, Vet. Microbiol. (1994) 40:111-124.

[21] Montague T., Warburton B., Non-toxic techniques for possum control, in: Montague $\mathrm{T}$. (Ed.), The brushtail possum: biology, impact 
and management of an introduced marsupial, Manaaki Whenua Press, Lincoln, New Zealand, 2000, pp. 164-1741.

[22] Morgan D., Hickling G., Techniques used for poisoning possums, in: Montague $\mathrm{T}$. (Ed.), The brushtail possum: biology, impact and management of an introduced marsupial, Manaaki Whenua Press, Lincoln, New Zealand, 2000, pp. 143-153.

[23] Morris R., Pfeiffer D., Jackson R., The epidemiology of Mycobacterium bovis infections, Vet. Microbiol. (1994) 40:153-177.

[24] New Zealand Biosecurity Act, Public Act 1993, No. 95, Wellington, New Zealand, 1993.

[25] Nörstrom M., Pfeiffer D., Jarp J., A spacetime cluster investigation of an outbreak of acute respiratory disease in Norwegian cattle herds, Prev. Vet. Med. (2000) 47:107-119.

[26] Norton S., Corner L., Morris R., Ranging behaviour and survival duration of wild brushtail possums (Trichosurus vulpecula) infected with Mycobacterium bovis, N. Z Vet. J. (2005) 53:293-300.

[27] O'Reilly L., Daborn C., The epidemiology of Mycobacterium bovis infections in animals and man: a review, Tuber. Lung Dis. (1995) $76: 1-46$

[28] Paterson B., Morris R., Interactions between beef cattle and simulated tuberculous possums on pasture, N. Z. Vet. J. (1995) 43:189193.

[29] Pharo H., Livingston P., Test to diagnose tuberculosis in cattle and deer in New Zealand, Surveillance (1997) 24:12-14.
[30] Ramsey D., Cowan P., Mortality rate and movements of brushtail possums with clinical tuberculosis (Mycobacterium bovis infection), N. Z. Vet. J. (2003) 51:179-185.

[31] Ramsey D., Ball S., Statistical limits of RTCI monitoring, Animal Health Board contractual report No. R-10590, Wellington, New Zealand, 2004.

[32] Rowlingson B., Diggle P., SPLANCS: Spatial point pattern analysis code in SPLUS, Comput. Geosci. UK (1993) 19:627655 .

[33] Ryan T., The New Zealand National Livestock Database, Kenya Vet. (1994) 18:325-327.

[34] Ryan T., Livingstone P., Ramsey D., de Lisle G., Nugent G., Collins D., Buddle B.M., Advances in understanding disease epidemiology and implications for control and eradication of tuberculosis in livestock: The experience from New Zealand, Vet. Microbiol. (2006) 112:211-219.

[35] Sanson R., Pearson A., Agribase - A national spatial farm database, Épidémiologie et Santé Animale (1997) 31-32:12.16.1112.16.13

[36] Sauter C., Morris R., Dominance hierarchies in cattle and red deer (Cervus elephus): Their possible relationship to the transmission of bovine tuberculosis, N. Z. Vet. J. (1995) 43:301-305.

[37] Weaver S., Policy implications of 1080 toxicology in New Zealand, J. Rural Remote Environ. Health (2003) 2:46-59. 